\title{
Antioxidant status of blood and liver of turkeys fed diets enriched with polyunsaturated fatty acids and fruit pomaces as a source of polyphenols
}

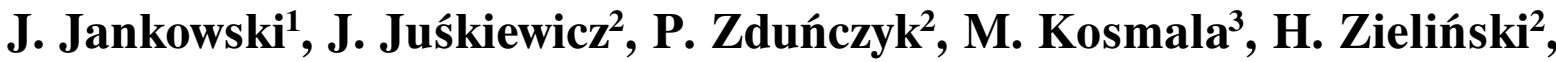 \\ Z. Antoszkiewicz ${ }^{4}, \mathrm{Z}$. Zduńczyk ${ }^{2}$ \\ ${ }^{1}$ Department of Poultry Science, Faculty of Animal Bioengineering, \\ University of Warmia and Mazury, Oczapowskiego 5, 10-719 Olsztyn, Poland \\ ${ }^{2}$ Institute of Animal Reproduction and Food Research, \\ Polish Academy of Sciences, Tuwima 10, 10-748 Olsztyn, Poland \\ ${ }^{3}$ Institute of Chemical Technology of Food, Lodz University of Technology, \\ Stefanowskiego 4/10, 90-924 Lodz, Poland \\ ${ }^{4}$ Department of Animal Nutrition and Feed Management, \\ University of Warmia and Mazury, Oczapowskiego 5, 10-719 Olsztyn, Poland
}

\begin{abstract}
It was hypothesized that dietary polyphenol-rich fruit pomaces can improve the antioxidant status of both diets and the tissues of turkeys fed such diets. Turkeys were fed diets containing a cellulose preparation (C) or 5\% dried apple pomace (AP), blackcurrant pomace (BCP), strawberry pomace (SP) and seedless strawberry pomace (SSP). Blood and liver biochemical parameters were determined in 7 birds from each experimental group slaughtered at 15 weeks of age, after 5 weeks of feeding diets containing soybean oil and linseed oil (approx. 1:1 ratio). Dietary linseed oil added to diets at $2.5 \%$ lowered the $n-6 / n-3$ PUFA ratio from approx. 7:1 to below 2:1, thus reducing the antioxidant properties of diets measured using DPPH, ABTS and photo-chemiluminescence assays, compared with diets containing only soybean oil and administered to birds in the first phase of feeding. Fruit pomaces, in particular SSP with the highest polyphenol content $(32.81 \mathrm{~g} / \mathrm{kg})$ and the highest antioxidant activity $(256.4 \mu \mathrm{M}$ Trolox/g), increased the antioxidant capacity of turkey diets. In comparison with the control group, the dietary treatments with fruit pomaces improved blood antioxidant parameters, including catalase activity (groups AP and $\mathrm{BCP}$ ), the total antioxidant capacity of hydrophilic (group AP) and lipophilic (groups AP, SP, and SSP) compounds, peroxide levels (groups AP and SSP) and antioxidant capacity measured by the FRAP (ferric reducing antioxidant power of plasma) assay (groups AP, BCP and SSP). Significantly lower concentrations of both vitamin E and thiobarbituric acid reactive substances (TBARS) were noted in the livers of turkeys fed all diets with dried fruit pomaces.
\end{abstract}

Key words: fruit pomace, antioxidant activity, blood plasma, liver, turkey

Correspondence to: Z. Zduńczyk, e-mail: z.zdunczyk@pan.olsztyn.pl 


\section{Introduction}

The inhibition of oxidative processes in the lipid fraction of the diet is an important consideration in fast-growing birds (Barroeta 2007). Poultry diets have long been supplemented with vegetable oils for economic reasons, and an increase in metabolizable energy concentrations in diets helps fast-growing birds reach their full genetic potential. A new trend involves modifying the fatty acid composition of meat to improve the n-6/n-3 PUFA ratio of the human diet (Zduńczyk and Jankowski 2013). The fatty acid profile of poultry meat can be modified with the use of dietary oils rich in $n-3$ polyunsaturated fatty acids (n-3 PUFAs), such as linseed oil (Jia et al. 2010).

Vitamin E and selenium are commonly used as antioxidants in poultry nutrition (Barroeta 2007). Research results indicate that plant polyphenols could be a new source of antioxidants in animal diets (Brenes et al, 2010, Sahin et al. 2010, Kamboh and Zhu 2013). The dietary grape seed extract has been found to contribute to and modulate the antioxidant activity of broiler chicken diets and excreta (Brenes et al. 2010). Diet supplementation with purified polyphenols increased vitamin $\mathrm{E}$ concentrations and decreased malondialdehyde (MDA) levels in the blood serum of Japanese quails (Sahin et al. 2010) and broiler chickens (Kamboh and Zhu 2013).

Pomace from fruit juice pressing can be a rich source of polyphenols in animal diets. In one experimen, the dietary inclusion of grape pomace as a source of polyphenols with powerful antioxidant capacity enhanced the antioxidant status of the diet, blood serum and excreta in broiler chickens, and increased lipid oxidation rates in meat (Goni et al. 2007). Beneficial effects of fruit pomaces on blood parameters were noted in piglets fed diets supplemented with apple pomace (Sehm et al. 2011) and in rats fed diets with polyphenol-rich strawberry pomace (Jaroslawska et al. 2011). Thus, polyphenol-rich fruit pomaces can be a source of natural antioxidants in animals diet with an increased vegetable oil content.

The aim of this study was to determine whether the inclusion of 5\% dried apple, blackcurrant and strawberry pomaces in turkey diets enriched with PUFAs can increase the antioxidant capacity of diets and improve selected metabolic parameters of birds, including the antioxidant status of the blood and liver.

\section{Materials and Methods}

\section{Birds, managements and diets}

The experiment was carried out at the Research Laboratory of the Department of Poultry Science,
University of Warmia and Mazury in Olsztyn (Poland). The experimental protocol was approved by the Local Animal Care and Use Committee (Olsztyn, Poland).

The experiment was performed on $525 \mathrm{Big} 7 \mathrm{fe}-$ male turkeys at the age of four weeks (with average initial body weight $0.93 \mathrm{~kg}$ ), divided into 5 groups of 105 birds each. Each group was kept in 7 pens with 15 birds per pen.

Experimental diets were supplemented with dried apple pomace (AP), blackcurrant pomace (BCP), strawberry pomace (SP) and seedless strawberry pomace (SSP) as an additional source of polyphenols. A cellulose preparation was added to the control diet (C) to level out its dietary fibre content to that in the experimental diets. Details regarding pomace drying, the chemical composition of dried fruit pomaces and the growth performance of turkeys in the full production cycle have been given in another paper (Juśkiewicz et al. 2014). In this study, we investigated the antioxidant effect of various fruit pomaces at two levels: (1) the antioxidant potential of experimental diets supplemented with different vegetable oils and (2) the antioxidant status of the blood and liver of turkeys fed diets rich in $n-3$ polyunsaturated fatty acids (n-3 PUFAs).

The composition of diets fed to turkeys is shown in Table 1. In the first feeding phase (5-9 weeks), the diets contained only soybean oil with a low level of $n-3$ PUFAs. In the second feeding phase (10-14 weeks), the diets were supplemented with linseed oil and the concentrations of n-3 PUFAs (more prone to oxidation) were increased. In all diets, $0.5 \%$ of the commercial premix Extramix provided equal amounts of vitamins, including vitamin A (all-trans-retinol acetate) - $13000 \mathrm{IU}$ and vitamin E (all-rac-tocopheryl acetate) $-40 \mathrm{mg}$.

\section{Growth trial and sample collection}

Antioxidant capacity was determined for all diets used in both feeding periods. At 15 weeks of age, 7 birds representing the average body weight per pen were selected from each treatment for blood and liver sample collection. Blood samples were collected from the wing vein into sterile tubes containing EDTA as anticoagulant for the analysis of biochemical and antioxidant status parameters. The birds were then euthanized and their livers were removed.

\section{Analysis of fatty acids, polyphenols and antioxidant capacity of diets}

For fatty acid analysis, minced feed and meat samples were extracted with a mixture of chloroform 
Table 1. Composition and nutritional value of diets fed to turkeys aged 5-9 and 10-14 weeks, \%.

\begin{tabular}{|c|c|c|c|c|c|c|c|c|}
\hline & \multicolumn{4}{|c|}{ Diet 1 (weeks 5-9) } & \multicolumn{4}{|c|}{ Diet 2 (weeks 10-14) } \\
\hline & $\mathrm{C}$ & AP & $\mathrm{BCP}$ & $\mathrm{SP}^{1}$ & $\mathrm{C}$ & $\mathrm{AP}$ & $\mathrm{BCP}$ & $\mathrm{SP}^{1}$ \\
\hline \multicolumn{9}{|l|}{ Component } \\
\hline Wheat & 31.3 & 28.27 & 29.51 & 29.45 & 58.54 & 55.33 & 57.61 & 57.59 \\
\hline Maize & 18.0 & 18.0 & 18.0 & 18.0 & - & - & - & - \\
\hline Soybean meal & 36.0 & 36.0 & 36.0 & 36.0 & 30.83 & 31.03 & 29.40 & 29.34 \\
\hline Potato protein & 4.62 & 4.72 & 3.88 & 3.84 & - & - & - & - \\
\hline Vitacel & 2.31 & - & - & - & 2.33 & - & - & - \\
\hline Apple pomace & - & 5.00 & - & - & - & 5.00 & - & - \\
\hline Black currant pomace & - & - & 5.00 & - & - & - & 5.00 & - \\
\hline Strawberry pomace & - & - & - & 5.00 & - & - & - & 5.00 \\
\hline Linseed oil & - & - & - & - & 2.50 & 2.50 & 2.50 & 2.50 \\
\hline Soybean oil & 2.92 & 3.24 & 2.83 & 2.92 & 2.84 & 3.17 & 2.52 & 2.60 \\
\hline Sodium bicarbonate & 0.10 & 0.10 & 0.10 & 0.10 & 0.10 & 0.10 & 0.10 & 0.10 \\
\hline Fodder salt & 0.25 & 0.25 & 0.25 & 0.25 & 0.14 & 0.14 & 0.14 & 0.14 \\
\hline Limestone & 1.58 & 1.58 & 1.58 & 1.58 & 1.23 & 1.22 & 1.23 & 1.23 \\
\hline Monocalcium phosphate & 1.79 & 1.82 & 1.81 & 1.81 & 0.55 & 0.57 & 0.57 & 0.57 \\
\hline DL-methionine $99 \%$ & 0.32 & 0.32 & 0.32 & 0.32 & 0.18 & 0.19 & 0.18 & 0.18 \\
\hline L-lysine $99 \%$ & 0.27 & 0.25 & 0.27 & 0.28 & 0.29 & 0.28 & 0.28 & 0.29 \\
\hline L-threonine & - & - & - & - & 0.07 & 0.07 & 0.07 & 0.07 \\
\hline Vitamin-mineral premix ${ }^{2}$ & 0.45 & 0.45 & 0.45 & 0.45 & 0.40 & 0.40 & 0.40 & 0.40 \\
\hline \multicolumn{9}{|l|}{ Nutritional value } \\
\hline Total protein & 25.5 & 25.5 & 25.5 & 25.5 & 21.5 & 21.5 & 21.5 & 21.5 \\
\hline Crude fibre & 3.96 & 3.96 & 4.99 & 4.53 & 3.96 & 3.96 & 4.94 & 4.48 \\
\hline $\mathrm{ME}, \mathrm{MJ} / \mathrm{kg}$ & 11.8 & 11.8 & 11.8 & 11.81 & 2.54 & 12. 54 & 12. 54 & 12.54 \\
\hline Lysine & 1.58 & 1.58 & 1.58 & 1.58 & 1.25 & 1.25 & 1.25 & 1.25 \\
\hline Met + Cys & 1.11 & 1.11 & 1.11 & 1.11 & 0.86 & 0.86 & 0.86 & 0.85 \\
\hline Threonine & 0.97 & 0.97 & 0.97 & 0.97 & 0.80 & 0.80 & 0.80 & 0.80 \\
\hline $\mathrm{Ca}$ & 1.15 & 1.15 & 1.15 & 1.15 & 0.75 & 0.75 & 0.75 & 0.75 \\
\hline $\mathrm{P}$ & 0.54 & 0.54 & 0.54 & 0.54 & 0.30 & 0.30 & 0.30 & 0.30 \\
\hline
\end{tabular}

${ }^{1}$ In the diet with seedless strawberry pomace, which had a higher total protein content, soybean meal was partially replaced with wheat.

${ }^{2} \mathrm{~T}$ he vitamin-mineral premix contained Ronozyme P and WX preparations.

and methanol (2:1 v:v), transesterified with Peisker's mixture (chloroform:methanol:sulfuric acid, 100:100:1, v:v:v), and subjected to gas chromatographic analysis using a $6890 \mathrm{~N}$ gas chromatograph (Agilent Technologies Inc., Palo Alto, CA) equipped with a flame ionization detector. Fatty acids were identified by their retention times and calculated levels of n-6 and n-3 PUFA in total FA. The content of saturated (SFAs), monounsaturated (MUFAs) and polyunsaturated (PUFAs) fatty acids as well as the n-6/n-3 PUFA ratio were calculated.

The total phenolic content of fruit pomaces and experimental diets was determined using the Folin-Ciocalteau reagent, as described by Singleton et al. (1999), and expressed in $\mathrm{mg}$ of gallic acid equivalents (GAE) per gram of diet. The antioxidant capacity of fruit pomaces was measured using the DPPH assay, according to the method of Hatano (Gow-Chin and Hui-Yin, 1995). The antioxidant capacity of experimental diets was determined as described by Zielińska et al. (2007). The antioxidant activity of diets was also measured using the ABTS assay, according to the method of Re et al. (1999), and the photochemiluminescence assay against superoxide anion radical $\left(\mathrm{O} 2^{-}\right)$, according to the method of Popov and Lewin (1999). The measurements for the ABTS test were carried out using a temperature-controlled UV-160 1PC spectrophotometer with a CPS-Controller (Shimadzu, Japan), and the results were expressed in $\mu \mathrm{mol}$ Trolox/g of sample. Based on the photochemiluminescence assay, the antioxidant capacity of hydrophilic (ACW) and lipophilic (ACL) extracts was determined using a Photochem ${ }^{\circledast}$ apparatus, and ACW and ACL analytical kits supplied by Analytik Jena (Leipzig, Germany) were used. Total antioxidant capacity was calculated as the sum of ACW and ACL values and was expressed as $\mu \mathrm{mol}$ Trolox/g of sample.

\section{Biochemical analysis of blood plasma and livers of turkeys}

As described previously (Zduńczyk et al., 2013), the following indicators of the antioxidant status were 
Table 2. The fatty acid profile of diets fed to turkeys aged 5-9 and 10-14 weeks, $\%$.

\begin{tabular}{|c|c|c|c|c|c|c|c|c|c|c|}
\hline & \multicolumn{5}{|c|}{ Diet 1 (weeks 5-9) } & \multicolumn{5}{|c|}{ Diet 2 (weeks 10-15) } \\
\hline & $\mathrm{C}$ & AP & $\mathrm{BCP}$ & SP & SSP & $\mathrm{C}$ & AP & $\mathrm{BCP}$ & SP & SSP \\
\hline $\mathrm{C} 14: 0$ & 0.20 & 0.18 & 0.20 & 0.20 & 0.19 & 0.09 & 0.08 & 0.09 & 0.10 & 0.09 \\
\hline $\mathrm{C} 15: 0$ & 0.04 & 0.03 & 0.04 & 0.04 & 0.03 & 0.05 & 0.03 & 0.05 & 0.05 & 0.05 \\
\hline C16:0 & 12.6 & 11.8 & 12.4 & 12.9 & 12.71 & 2.6 & 10.7 & 12.6 & 13.6 & 13.2 \\
\hline C16:1 & 0.26 & 0.23 & 0.24 & 0.23 & 0.22 & 0.14 & 0.11 & 0.14 & 0.14 & 0.13 \\
\hline $\mathrm{C} 17: 0$ & 0.11 & 0.09 & 0.12 & 0.14 & 0.14 & 0.15 & 0.10 & 0.17 & 0.20 & 0.22 \\
\hline $\mathrm{C} 17: 1$ & 0.06 & 0.06 & 0.05 & 0.05 & 0.06 & 0.06 & 0.06 & 0.06 & 0.07 & 0.07 \\
\hline C18:0 & 3.62 & 3.29 & 3.61 & 3.79 & 3.77 & 4.05 & 3.68 & 4.04 & 4.24 & 4.21 \\
\hline C18:1 & 24.8 & 22.8 & 24.4 & 25.8 & 25.22 & 1.6 & 19.9 & 21.3 & 22.6 & 22.4 \\
\hline C18:2 n-6 & 49.7 & 50.9 & 49.9 & 48.1 & 48.23 & 9.6 & 41.6 & 39.0 & 38.3 & 38.3 \\
\hline C18:3 n-3 & 7.02 & 7.80 & 7.36 & 6.96 & 7.04 & 20.5 & 22.8 & 21.5 & 19.6 & 19.9 \\
\hline C20:0 & 0.48 & 0.45 & 0.52 & 0.51 & 0.54 & 0.30 & 0.28 & 0.34 & 0.33 & 0.43 \\
\hline C20:1 & 0.68 & 0.63 & 0.73 & 0.71 & 0.70 & 0.25 & 0.23 & 0.27 & 0.26 & 0.26 \\
\hline$C 20: 2$ n-6 & nd & nd & nd & nd & nd & 0.09 & 0.04 & 0.05 & 0.04 & 0.19 \\
\hline C20:4 n-6 & nd & nd & nd & nd & nd & 0.06 & 0.08 & 0.05 & 0.03 & 0.09 \\
\hline C22:0 & 0.38 & 0.37 & 0.44 & 0.41 & 0.40 & 0.33 & 0.32 & 0.35 & 0.36 & 0.36 \\
\hline$C 22: 6 n-3$ & nd & nd & nd & nd & nd & 0.15 & 0.09 & 0.04 & 0.06 & 0.10 \\
\hline $\mathrm{SFA}^{1}$ & 17.4 & 16.2 & 17.3 & 18.0 & 17.0 & 17.6 & 15.2 & 17.7 & 18.9 & 18.6 \\
\hline MUFA $^{2}$ & 25.8 & 23.7 & 25.4 & 26.8 & 26.2 & 22.0 & 20.3 & 21.7 & 23.1 & 22.9 \\
\hline PUFA $^{3}$ & 56.8 & 58.7 & 56.3 & 55.1 & 55.2 & 60.4 & 64.6 & 60.6 & 58.1 & 58.6 \\
\hline n-6 PUFA ${ }^{4}$ & 49.7 & 50.9 & 48.9 & 48.1 & 48.2 & 39.8 & 41.8 & 39.1 & 38.4 & 38.6 \\
\hline n-3 PUFA ${ }^{5}$ & 7.02 & 7.80 & 7.36 & 6.96 & 7.04 & 20.7 & 22.9 & 21.5 & 19.7 & 20.0 \\
\hline$n-6 / n-3$ ratio & 7.08 & 6.52 & 6.64 & 6.91 & 6.84 & 1.92 & 1.81 & 1.81 & 1.95 & 1.93 \\
\hline
\end{tabular}

${ }^{1}$ SFA - saturated fatty acids

${ }^{2}$ MUFA - monounsaturated fatty acids

${ }^{3}$ PUFA - polyunsaturated fatty acids

${ }^{4}$ n-6 PUFA - C18:2 n-6 fatty acid

${ }^{5}$ n-3 PUFA - C18:3 n-3 fatty acid

determined in the blood plasma of turkeys: the concentration of uric acid, hydrogen peroxide, ascorbic acid, tocopherols and retinol, the activities of catalase and superoxide dismutase, and the ferric reducing ability of plasma (FRAP). The antioxidant capacity of blood plasma resulting from the presence of hydrophilic and lipolitic antioxidants was determined by a photochemiliminescence detection method using PHOTOCHEM (Analytik Jena AG, Germany).

\section{Statistical analysis}

Statistical analysis was performed using one-way analysis of variance (ANOVA), according to the GLM procedure for Statistica 8.0PL software.

\section{Results}

\section{Fatty acid profile, polyphenol content and antioxidant capacity of diets}

No differences in the fatty acid (FA) profiles of the control diet and diets supplemented with fruit pomaces were observed in either feeding phase
(Table 2). Significant differences in the FA profile were reported between diets fed to turkeys at the age of 5-9 weeks and 10-14 weeks. In the first feeding phase, n-3 PUFAs accounted for less than $8 \%$ of total fatty acids, and the n-6/n-3 PUFA ratio was close to 7:1. In the second phase, after linseed oil application, the share of n-3 PUFAs in the total FA pool increased by approx. $30 \%$, whereas the $n-6 / n-3$ PUFA ratio decreased below 2:1.

The polyphenol content of the analysed fruit pomaces ranged from $5.75 \mathrm{~g} \mathrm{GAE} / \mathrm{kg}$ in $\mathrm{AP}$ to $32.81 \mathrm{~g} \mathrm{GAE} / \mathrm{kg}$ in SSP; however, the antioxidant activity of pomaces ranged from $32.0 \mu \mathrm{mol}$ Trolox/g in AP to $256.4 \mu \mathrm{mol}$ Trolox/g in SSP (Fig. 1). The differences in the antioxidant activity of BCP and SP (102.8 vs. $84.7 \mu \mathrm{mol}$ Trolox/g) were considerably higher than the variations in their polyphenol concentrations (12.43 vs. $11.51 \mathrm{~g} \mathrm{GAE} / \mathrm{kg}$ ).

The experimental diets differed in their total polyphenol content, antioxidant activity and antioxidant capacity, subject to the added fruit pomade (Table 3). The polyphenol content of control diets was determined at 1.82 and $1.27 \mathrm{~g} \mathrm{GAE} / \mathrm{kg}$ in the first and second feeding phases, respectively. Fruit pomaces increased polyphenol concentrations in diets by up to $0.28 \mathrm{~g} \mathrm{GAE} / \mathrm{kg}$ in the first phase and $0.31 \mathrm{~g} \mathrm{GAE} / \mathrm{kg}$ in 


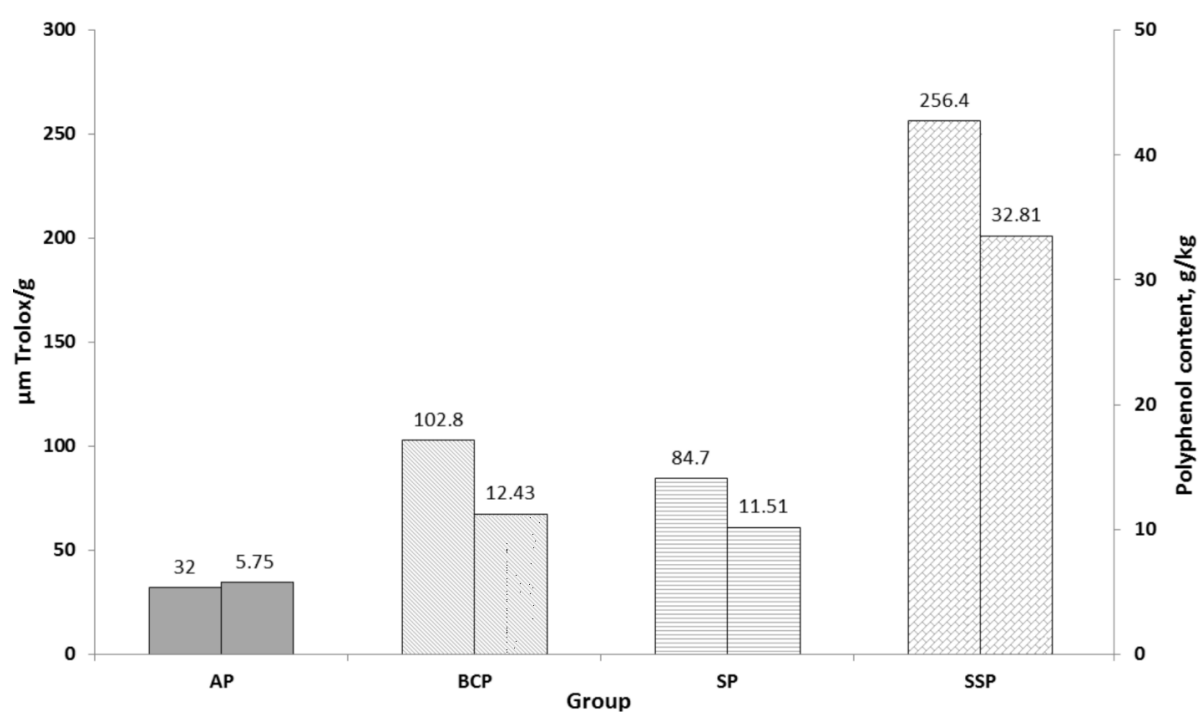

Fig. 1. Total polyphenol (g GAE/kg) and DPPH scavenging activity ( $\mu$ mol Trolox $/ \mathrm{g}$ ) of fruit pomaces.

Table 3. Polyphenol content and antioxidant capacity of diets containing soybean oil (diet 1) or soybean oil and linseed oil (diet 2) and cellulose or fruit pomace.

\begin{tabular}{|c|c|c|c|c|c|}
\hline & \multicolumn{5}{|c|}{ Groups $^{1}$} \\
\hline & $\mathrm{C}$ & $\mathrm{AP}$ & $\mathrm{BCP}$ & SP & SSP \\
\hline \multicolumn{6}{|l|}{ Diet 1 (weeks 5-9) } \\
\hline Polyphenol content, $\mathrm{g} / \mathrm{kg}$ & 1.82 & 1.88 & 1.98 & 2.03 & 2.10 \\
\hline \multicolumn{6}{|l|}{ Antioxidant activity, } \\
\hline DPPH, $\mu \mathrm{mol} \mathrm{TE} / \mathrm{g}$ & 3.25 & 4.01 & 4.32 & 4.40 & 5.17 \\
\hline ABTS, $\mu \mathrm{mol} \mathrm{TE} / \mathrm{g}$ & 8.36 & 8.65 & 9.33 & 9.07 & 10.08 \\
\hline \multicolumn{6}{|l|}{ Antioxidant capacity } \\
\hline Hydrophilic extract & 1.33 & 1.61 & 2.03 & 2.11 & 2.31 \\
\hline Lipophilic extract & 0.27 & 0.39 & 0.42 & 0.53 & 0.53 \\
\hline Total antioxidant capacity & 1.60 & 2.00 & 2.45 & 2.64 & 2.84 \\
\hline \multicolumn{6}{|l|}{ Diet 2 (weeks 10-14) } \\
\hline Polyphenol content, $\mathrm{g} / \mathrm{kg}$ & 1.27 & 1.45 & 1.48 & 1.48 & 1.58 \\
\hline \multicolumn{6}{|l|}{ Antioxidant activity } \\
\hline DPPH, $\mu \mathrm{mol} \mathrm{TE} / \mathrm{g}$ & 1.33 & 1.65 & 1.91 & 1.93 & 2.16 \\
\hline ABTS, $\mu \mathrm{mol} \mathrm{TE} / \mathrm{g}$ & 7.71 & 7.89 & 8.18 & 8.23 & 9.55 \\
\hline \multicolumn{6}{|l|}{ Antioxidant capacity } \\
\hline Hydrophilic extract & 0.71 & 1.24 & 1.31 & 1.42 & 1.73 \\
\hline Lipophilic extract & 0.29 & 0.36 & 0.48 & 0.58 & 0.48 \\
\hline Total antioxidant capacity & 1.00 & 1.60 & 1.79 & 2.00 & 2.21 \\
\hline
\end{tabular}

${ }^{1} \mathrm{C}$ - cellulose, AP - apple pomace, BCP - black currant pomace, SP - strawberry pomace, SSP - seedless strawberry pomace ${ }^{2}$ Diet 1 contained $2.83-3.24 \%$ soybean oil, Diet 2 contained $2.5 \%$ linseed oil and $2.52-3.17 \%$ soybean oil

the second phase. In both feeding phases, the highest increase in polyphenol concentrations was induced by the addition of SSP, and the lowest increase - by the addition of AP, by $0.06 \mathrm{~g} \mathrm{GAE} / \mathrm{kg}$ and $0.15 \mathrm{~g} \mathrm{GAE} / \mathrm{kg}$ in diets 1 and 2, respectively.

Fruit pomace affected the antioxidant potential in the experimental diets (Table 3). In comparison with the control diet, the lowest increase in DPPH and ABTS values was noted in diet AP, and the highest in diet SSP. The values of antioxidant activity provided by both assays were similar in diets BCP and SP. In the first feeding phase, when the diets were enriched with soybean oil only, antioxidant activity was higher than in the second phase when both soybean oil and linseed oil $(2.5 \%)$ were added. In both periods, the hydrophilic fraction was the main contributor to plasma antioxidant capacity. In comparison with the control group, the highest increase in the antioxidant capacity of the hydrophilic fraction was observed in diet SSP: from 1.33 to $2.31 \mathrm{fmol}$ Trolox/g in the first phase, and from 0.71 to $1.73 \mathrm{fmol}$ Trolox/g in the second phase. Moreover, diet SSP was also characterized by an over two-fold higher total antioxidant capacity (vs. C diet), especially due to nearly a two-fold 


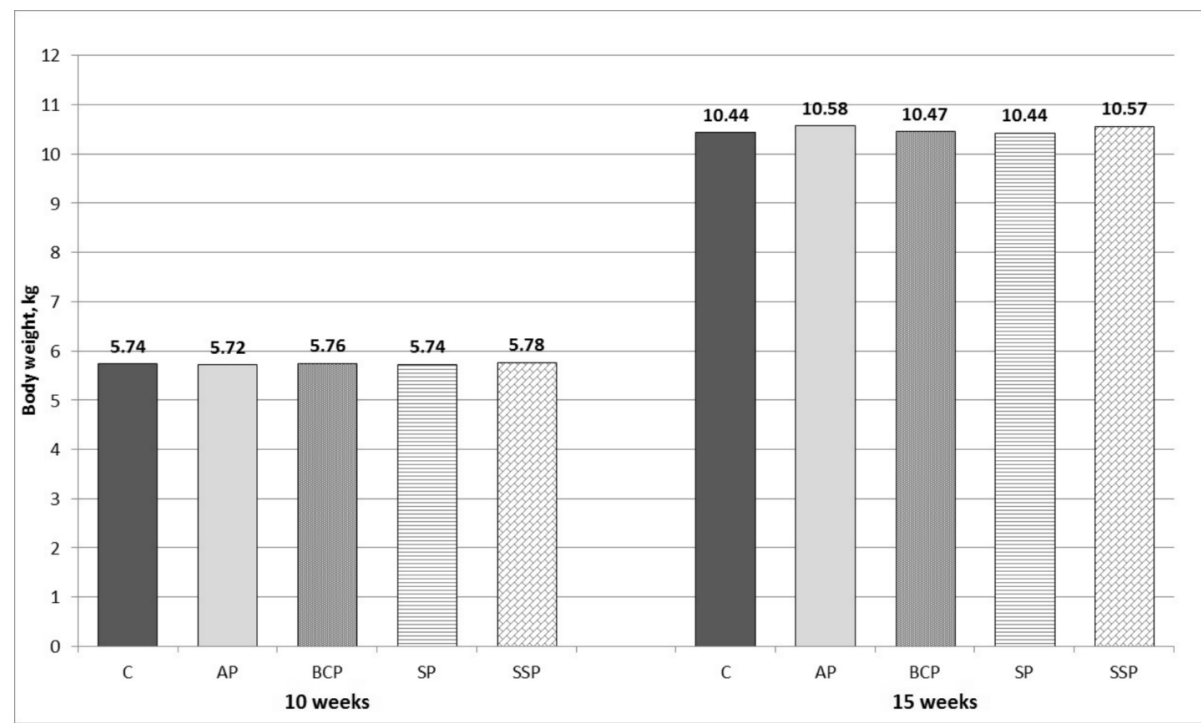

Fig. 2. Body weights of turkeys fed the control diet (C) and diets with different sources of fruit polyphenols: apple (AP), blackcurrant (BCP), strawberry (SP) and seedless strawberry (SSP) pomace.

Table 4. Parameters of the plasma and liver antioxidant status in turkeys.

\begin{tabular}{|c|c|c|c|c|c|c|c|}
\hline & \multicolumn{5}{|c|}{ Groups $^{1}$} & \multirow{2}{*}{ SEM } & \multirow{2}{*}{$P$} \\
\hline & $\mathrm{C}$ & AP & $\mathrm{BCP}$ & SP & SSP & & \\
\hline \multicolumn{8}{|l|}{ Blood plasma } \\
\hline Vitamin $A, \mu \mathrm{g} / \mathrm{mL}$ & 2.52 & 2.30 & 2.20 & 2.24 & 2.02 & 0.073 & 0.060 \\
\hline Vitamin $\mathrm{E}, \mu \mathrm{g} / \mathrm{mL}$ & $1.00^{\mathrm{a}}$ & $0.80^{\mathrm{b}}$ & $0.94^{\mathrm{a}}$ & $0.74^{\mathrm{b}}$ & $0.69^{\mathrm{b}}$ & 0.024 & 0.001 \\
\hline Vitamin $C, \mu \mathrm{g} / \mathrm{L}$ & $113^{\mathrm{b}}$ & $145^{\mathrm{ab}}$ & $202^{\mathrm{a}}$ & $146^{\mathrm{b}}$ & $142^{\mathrm{ab}}$ & 9.00 & 0.049 \\
\hline $\mathrm{SOD}^{2}, \mathrm{U} / \mathrm{Ml}$ & 25.3 & 25.2 & 25.2 & 25.2 & 25.17 & 0.027 & 0.263 \\
\hline Catalase, U/Ml & $5.39^{\mathrm{b}}$ & $7.14^{\mathrm{a}}$ & $7.02^{\mathrm{a}}$ & $6.15^{\mathrm{ab}}$ & $5.75^{\mathrm{b}}$ & 0.182 & 0.002 \\
\hline $\mathrm{ACW}^{3}, \mu \mathrm{g} \mathrm{AA} / \mathrm{mL}$ & $0.233^{\mathrm{b}}$ & $0.341^{\mathrm{a}}$ & $0.226^{\mathrm{b}}$ & $0.244^{\mathrm{b}}$ & $0.190^{c}$ & 0.009 & 0.001 \\
\hline $\mathrm{ACL}^{4}, \mu \mathrm{g}$ Trolox $/ \mathrm{mL}$ & $0.060^{\mathrm{b}}$ & $0.076^{\mathrm{a}}$ & $0.064^{\mathrm{b}}$ & $0.080^{\mathrm{a}}$ & $0.074^{\mathrm{a}}$ & 0.001 & 0.001 \\
\hline $\mathrm{H}_{2} \mathrm{O}_{2}^{5}, \mu \mathrm{mol} / \mathrm{L}$ & $4.18^{\mathrm{a}}$ & $2.66^{\mathrm{c}}$ & $3.82^{\mathrm{ab}}$ & $3.72^{\mathrm{ab}}$ & $3.46^{\mathrm{b}}$ & 0.106 & 0.001 \\
\hline $\mathrm{FRAP}^{6}, \mu \mathrm{mol} / \mathrm{L}$ & $20.4^{\mathrm{c}}$ & $50.2^{\mathrm{a}}$ & $43.4^{\mathrm{ab}}$ & $31.3^{\mathrm{bc}}$ & $56.0^{\mathrm{a}}$ & 2.821 & 0.001 \\
\hline \multicolumn{8}{|l|}{ Liver } \\
\hline Vitamin $\mathrm{A}, \mu \mathrm{g} / \mathrm{g}$ & 72.6 & 73.2 & 75.8 & 75.5 & 78.9 & 5.250 & 0.112 \\
\hline Vitamin $E, \mu g / g$ & $10.0^{\mathrm{a}}$ & $3.35^{\mathrm{b}}$ & $4.59^{\mathrm{b}}$ & $4.08^{b}$ & $3.27^{\mathrm{b}}$ & 0.485 & 0.001 \\
\hline TBARS $^{7}, \mu \mathrm{g} / \mathrm{g}$ & $4.66^{\mathrm{a}}$ & $2.80^{\mathrm{c}}$ & $3.70^{\mathrm{b}}$ & $3.39^{\mathrm{bc}}$ & $3.33^{\mathrm{bc}}$ & 0.146 & 0.001 \\
\hline
\end{tabular}

${ }^{1} \mathrm{AP}$ - apple pomace, BCP - black currant pomace, SP - strawberry pomace, SSP - seedless strawberry pomade,

${ }^{2} \mathrm{SOD}$ - Superoxide dismutase activity,

${ }^{3} \mathrm{H}_{2} \mathrm{O}_{2}$ - hydrogen peroxide concentrations,

${ }^{4} \mathrm{ACW}$ - antioxidant capacity of hydrophilic fraction,

${ }^{5}$ ACL - antioxidant capacity of lipophilic fraction,

${ }^{6}$ FRAP - ferric reducing ability of plasma,

${ }^{7}$ TBARS - thiobarbituric acid reactive substances,

a, b, c - values in rows followed by different superscript letters are significantly different $(p=0.05)$,

SEM - standard error of the mean (SD for all birds divided by the square root of the number of all birds, $\mathrm{n}=35$ )

increase in the antioxidant capacity of the lipophilic fraction. In comparison with SSP, the remaining fruit pomaces (AP, BCP and SP) induced a visible but lower increase in the antioxidant capacity of hydrophilic and lipophilic fractions.

\section{Body weights of turkeys and antioxidant status of their blood plasma and livers}

At 10 and 15 weeks of age, the body weights of turkeys were similar in all experimental groups (Fig. 2). 
The dietary treatments differentiated selected parameters of the antioxidant status in the blood plasma of turkeys (Table 4). Group BCP was characterized by the highest vitamin $\mathrm{C}$ concentrations, which differed significantly relative to the control group and group SP $(p=0.049)$. No differences in plasma vitamin A levels were noted between groups, whereas vitamin $\mathrm{E}$ concentrations in groups $\mathrm{C}$ and $\mathrm{BCP}$ were significantly higher than in groups AP, SP and SSP $(p=0.001)$. Plasma SOD activity was similar in all groups, and catalase activity was significantly higher in groups $\mathrm{AP}$ and $\mathrm{BCP}$ than in groups $\mathrm{C}$ and SSP $(p=0.002)$. Groups $\mathrm{C}$ and $\mathrm{BCP}$ were characterized by lower antioxidant capacity of the lipophilic fraction (ACL) in the blood plasma $(p=0.001)$. The antioxidant capacity formed by hydrophilic compounds $(\mathrm{ACW})$ was highest in group AP and lowest in group SSP, and significant differences $(p=0.009)$ were noted relative to the remaining groups. Lipid peroxide concentrations in the blood plasma were highest in group $\mathrm{C}$ and significantly lower in groups AP and SSP $(p=0.001)$. FRAP levels were highest in groups AP and SSP - significantly higher than in groups $\mathrm{C}$ and $\mathrm{SP}(p=0.001)$.

No differences in the vitamin A content of turkey livers were observed between groups, whereas vitamin E concentrations in the livers of group $\mathrm{C}$ turkeys were significantly higher $(P=0.001)$ than in the remaining groups. Group $\mathrm{C}$ was also characterized by the highest TBARS concentrations.

\section{Discussion}

Linoleic acid accounts for approximately 50\%, and linolenic acid for less than $10 \%$, of the fatty acid profile of soybean oil (Fébel et al. 2008, Kavouridou et al. 2008). Linseed oil contains significantly less linoleic acid and significantly more linolenic acid than soybean oil (Kavouridou et al. 2008, Jankowski et al. 2012). In the present study, diets enriched with linseed oil were characterized by a higher linolenic acid content and more than a three-fold lower $n-6 / n-3$ PUFAs ratio.

According to other authors (Helbig et al. 2008), fruit seed oil is abundant in $\alpha$-linolenic acid. In our experiment, oil concentrations in fruit pomaces added at $5 \%$ to turkey diets were low (up to $0.7 \%$ ) and did not affect the FA profile of the diet.

Polyunsaturated fatty acids, in particular n-3 PUFAs, are more susceptible to oxidation than acids with a lower degree of unsaturation (Decker et al. 2005). For this reason, the intake of PUFA should be accompanied by increased levels of vitamin $\mathrm{E}$ and other antioxidants, which are essential for the anti- oxidant protection of feed and animal tissue. The above observation was probably the key factor responsible for the decrease in the antioxidant activity of diets fed to turkeys at the age of 10-14 weeks in comparison with the diets administered at the age of 5-9 weeks. The addition of linseed oil to diets in the second feeding phase increased the content of n-3 PUFAs in the total FA pool from approx. $7 \%$ to approx. $20 \%$, and lowered the n-6/n-3 PUFAs ratio from approx. 7:1 to below 2:1.

In our study, the total polyphenol content of apple pomace was determined at $5.75 \mathrm{~g} \mathrm{GAE} / \mathrm{kg}$, and it was within the range given by other authors (Suarez et al. 2010). Polyphenol concentrations were twice as high in blackcurrant and strawberry pomaces than in apple pomace. Similar results were reported by other authors (Suarez et al. 2010; Jaroslawska et al. 2011) who found that polyphenol concentrations in fruit pomace are proportional to the polyphenol content of fresh fruit, and that berries are more abundant in polyphenols than apples (Perez-Jimenez et. al. 2010). Seedless strawberry pomace was the richest source of polyphenols due to higher polyphenol concentrations in the pulp and a lower drying temperature (Juśkiewicz et al. 2015).

In this experiment, the replacement of a cellulose preparation in the control diet with fruit pomaces led to a relatively low increase in polyphenol concentrations: from 1.82 to $1.88-2.10 \mathrm{~g} \mathrm{GAE} / \mathrm{kg}$ in diets fed to turkeys aged 5-9 weeks, and from 1.27 to $1.45-1.58$ $\mathrm{g} \mathrm{GAE} / \mathrm{kg}$ in diets fed to turkeys aged 10-14 weeks.

The polyphenol content of diets is difficult to establish due to variations in polyphenol solubility, which can produce significant errors (Saura-Calixto et al. 2007). The commonly used colorimetric method of the Folin Ciocalteu (FC) reaction forms a blue chromophore constituted by a phosphotungstic-phosphomolybdenum complex, where the maximum absorption of the chromophores depends on the alkaline solution and the concentration of phenolic compounds (Singleton et al. 1999). Due to the complexity of the competing reactions involved in the F-C method, reaction equilibrium is fairly unstable, and it is not easy to find the exact conditions for the assay. An important drawback/limitation of the F-C method is that precipitates can form under certain conditions (Cicco and Lattanzio 2011). Polyphenols can chelate transition metal ions, such as iron and copper, decreasing their ability to promote reactive species formation (Halliwell 2007). In view of the high content of added macroelements, microelements and vitamins in poultry diets, polyphenol concentrations determined by the F-C method should be regarded only as a general reference.

In our study, lower polyphenol concentrations 
were reported in all diets administered in the second feeding phase, which could result from the lower soybean content of diets fed to older turkeys. Soybeans and soybean products are rich in polyphenols, in particular isoflavones (Malencic et al. 2012), and the polyphenol content of wheat, which was added in larger amounts to diets in the second phase, is approximately three-fold lower in comparison with soybeans (Perez-Jimenez et al. 2010).

The antioxidant activity of apple pomace noted in this study was similar to that observed by other authors (Bai et al. 2013). In our experiment, the antioxidative potential of black currant pomace and strawberry pomace was 2.5 -fold higher compared with apple pomace. The antioxidative potential of pomaces correlated with their polyphenol content. In other studies, similar correlations were reported in apple, currant and strawberry pomaces (Sikora et al. 2007) and in pomaces made from different apple varieties (Suarez et al. 2010). In this experiment, the antioxidant activity of seedless strawberry pomace was more than two-fold higher that that of strawberry pomace.

The antioxidant properties of polyphenol compounds have been confirmed in many in vitro experiments (Halliwell 2007). Phenolic content generally correlates with antioxidant capacities measured by DPPH or ABTS methods (Tabart et al. 2009). Other studies indicate that the DPPH assay effectively determines the most reactive antioxidant components (Kim et al. 2002), whereas the ABTS* assay measures the antioxidant activity of a wider range of polyphenolic compounds (Re et al. 1999). In this study, the lowest increase in antioxidant status indicators relative to the control diet was noted in diet AP in both assays. Diet SSP was characterized by the highest antioxidant activity and antioxidant capacity compared with the control diet. The antioxidant capacity of all diets was determined mainly by the hydrophilic fraction and, to a lesser extent, by the lipophilic fraction of fruit pomaces.

The results of many experiments conducted in the last decade indicate that plant polyphenol extracts can be regarded as a new source of antioxidants in animal nutrition (Sahin et al. 2010, Kamboh and Zhu 2013). Jiang et al. (2007) reported a dose-dependent increase in plasma total antioxidant activity of broilers whose diets were supplemented with 10 to $80 \mathrm{mg} / \mathrm{kg}$ of soy flavonoids. An improvement in plasma antioxidant parameters, including total antioxidant activity and MDA concentrations, was reported when broiler diets were supplemented with grape-derived resveratrol (Sahin et al. 2010), rosemary, green tea and grape seed extracts (Vossen et al. 2011), and purified genis- tein and hesperidin (Kamboh and Zhu 2013). Similar results were noted in our study where the addition of fruit pomaces, in particular seedless strawberry pomace, improved selected parameters of antioxidant status in the blood plasma, including an increase in vitamin C levels, catalase activity, capacity of hydrophilic and lipophilic fractions, and FRAP values, and a decrease in plasma peroxide levels and TBARS values in turkey livers. We were unable to explain the observed decrease in vitamin $\mathrm{E}$ concentrations in the blood plasma and livers of turkeys.

According to some authors, the existing research findings do not support the generalization that supplements containing polyphenols can effectively replace vitamin $\mathrm{E}$, the most important lipophilic antioxidant in mammals (Wolffram et al. 2009). A study of growing rats revealed that dietary flavonoids do not affect vitamin E status (Wiegand et al. 2009). Very few studies have been conducted on poultry, and they produced inconsistent results regarding the direction and range of the antioxidant effects of polyphenols in birds. Jiang et al. (2007) reported that dietary isoflavones from soybean increase SOD activity and decreased plasma TBARS levels in broiler chickens, whereas other authors demonstrated that dietary supplementation with purified flavonoids increased only blood vitamin $\mathrm{E}$ concentrations in Japanese quails (Sahin et al. 2010). In another experiment, an increase in GSH-Px activity and a tendency towards higher levels of SOD activity were not accompanied by changes in the FRAP or TBARS values in the blood of broilers (Vossen et al. 2011).

In our study, the use of polyphenol-rich fruit pomaces in diets did not increase the concentrations of fat-soluble vitamins in the blood and livers of turkeys. Vitamin A levels were similar in all groups, whereas vitamin $\mathrm{E}$ concentrations were significantly lower in experimental groups than in the control group. The above could be attributed to both antioxidant and prooxidant effects of polyphenols in vivo (Jonson and Loo 2000). According to Halliwell (2007), dietary polyphenols are typical xenobiotics which are metabolized as such and rapidly removed from circulation. Easily oxidized low-molecular-weight phenolic compounds, such as quercetin and gallic acid, probably deliver prooxidant effects, whereas high-molecular-weight phenolic compounds, such as procyanidins, have little or no prooxidant activity (Hagerman et al. 1998). In fruit pomaces, the polyphenols are generally bound to fibre and are released by bacteria in the lower gastrointestinal tract (Brenes et al. 2010), which decrease their pro-oxidant capacity in comparison with low-molecular-weight polyphenols that are absorbed in the upper gastrointestinal tract. 


\section{Conclusions}

It can be concluded that dried fruit pomaces increased the polyphenol content and antioxidant capacity of turkey diets. An improvement was also noted in antioxidant status indicators, including an increase in vitamin $\mathrm{C}$ concentrations, a decrease in lipid peroxide levels, an increase in the antioxidant capacity of blood plasma hydrophilic and lipophilic fractions, and a decrease in hepatic TBARS concentrations. Vitamin E concentrations decreased in the plasma and livers of turkeys, which is difficult to explain.

\section{References}

Bai X, Zhang H, Ren S (2013) Antioxidant activity and HPLC analysis of polyphenol-enriched extracts from industrial apple pomace. J Sci Food Agric 93: 2502-2506.

Barroeta AC (2007) Nutritive value of poultry meat: relationship between vitamin E and PUFA. World's Poult Sci J 63: 277-284.

Brenes A, Viveros A, Goni I, Centeno C, Saura-Calixto F, Arija I (2010) Effect of grape seed extract on growth performance, protein and polyphenol digestibilities, and antioxidant activity in chickens. Span J Agric Res 8: 326-333.

Cicco N, Lattanzio V (2011) The influence of initial carbonate concentration on the Folin-Ciocalteu micro-method for the determination of phenolics with low concentration in the presence of methanol: a comparative study of real-time monitored reactions. Am J Anal Chem 2: $840-848$.

Decker EA, Warner K, Richards MP, Shahidi F (2005) Measuring antioxidant effectiveness in food. J Agric Food Chem 53: 4303-4310.

Fébel H, Mézes M, Pálfy T, Hermán A, Gundel J, Lugasi A, Balogh K, Kocsis I, Blázovics A (2008) Effect of dietary fatty acid pattern on growth, body fat composition and antioxidant parameters in broiler. J Anim Physiol Anim Nutr 92: 369-376.

Goni I, Brenes A, Centeno C, Viveros A, Saura-Calixto F, Rebole A, Arija I, Estevez R (2007) Effect of dietary grape pomace and vitamin $\mathrm{E}$ on growth performance, nutrient digestibility, and susceptibility to meat lipid oxidation in chickens. Poult Sci 86: 508-516.

Hagerman AE, Riedl KM, Jones GA, Sovik KN, Ritchard NT, Hartzfeld PW, Riechel TL, (1998) High molecular weight plant polyphenolics (tannins) as biological antioxidants. J Agric Food Chem 46: 1887-1892.

Halliwell B (2007) Dietary polyphenols: good, bad or indifferent for your health? Cardiovasc Res 73: 341-347.

Helbig D, Böhm V, Wagner A, Schubert R, Jahreis G (2008) Berry seed press residues and their valuable ingredients with special regard to black currant seed press residues. Food Chem 111: 1043-1049.

Jankowski J, Zduńczyk P, Mikulski D, Zduńczyk Z, Juśkiewicz J Mikulska M, Zduńczyk Z (2012) Effects of dietary soybean, rapeseed and linseed oils on performance, slaughter yield and fatty acid profile of breast meat in turkeys. J Anim Feed Sci 21: 143-156.
Jaroslawska J, Juśkiewicz J, Wróblewska M, Jurgoński A, Król B, Zduńczyk Z (2011) Polyphenol-rich strawberry pomace reduces serum and liver lipids and alters gastrointestinal metabolite formation in fructose-fed rats. J Nutr 141: 1777-1783.

Jia W, Rogiewicz A, Bruce HL, Slominski BA (2010) Feeding flaxseed enhances deposition of omega-3 fatty acid in broiler meat portions in different manner. Can J Anim Sci 90: 203-206.

Jiang ZY, Jiang SQ, Lin YC, Xi PB, Yu DQ, Wu TX (2007) Effects of soybean isoflavone on growth performance, meat quality, and antioxidation in male broilers. Poult Sci 86: $356-1362$.

Juśkiewicz J, Jankowski J, Zdunczyk Z, Kołodziejczyk K, Mikulski D, Zdunczyk P (2015) The chemical composition of selected fruit pomaces and their effects on the growth performance and post-slaughter parameters of young turkeys. J Anim Feed Sci 24: 53-60.

Kamboh AA, Zhu WY (2013) Effect of increasing levels of bioflavonoids in broiler feed on plasma anti-oxidative potential, lipid metabolites, and fatty acid composition of meat. Poult Sci 92: 454-461.

Kavouridou K, Barroeta AC, Villaverde C Manzanilla EG, Baucells MD (2008) Fatty acid, protein and energy gain of broilers fed different dietary vegetable oils. Span J Agric Res 6: 210-218.

Kim D-O, Lee KW, Lee HJ, Lee CY (2002) Vitamin $\mathrm{C}$ equivalent antioxidant capacity (VCEAC) of phenolic phytochemicals. J Agric Food Chem 50: 3713-3717.

Malencic D, Cvejic J, Miladinovic J (2012) Polyphenol content and antioxidant properties of colored soybean seeds from central Europe. J Med Food 15: 89-95.

Perez-Jimenez J, Neveu V, Vos F, Scalbert A (2010) Identification of the 100 richest dietary sources of polyphenols: an application of the Phenol-Explorer database. Eur J Clin Nutr 64 (Suppl 3): S112-S120.

Popov I, Lewin G (1999) Antioxidative homeostasis: Characterisation by means of chemiluminescent technique in methods in enzymology. In Packer L (ed) Oxidants and Antioxidants, part B. Academic Press, 300, pp 96-100.

Re R, Pellegrini N, Proteggente A, Pannala A, Yang M, Rice-Evans C (1999) Antioxidant activity applying an improved ABTS radical cation decolorization assay. Free Radic Biol Med 26: 1231-1237.

Sahin K, Orhan C, Tuzcu M, Ali S, Sahin N, Hayirli A (2010) Epigallocatechin-3-gallate prevents lipid peroxidation and enhances antioxidant defense system via modulating hepatic nuclear transcription factors in heat-stressed quails. Poult Sci 89: 2251-2258.

Sehm J, Treutter D, Lindermayer H, Meyer HH, Pfaffl MW (2011) The influence of apple- or red-grape pomace enriched piglet diet on blood parameters, bacterial colonisation, and marker gene expression in piglet white blood cells. Food Nutr Sci 2: 366-376.

Sikora J, Markowicz M, Mikiciuk-Olasik E (2009) The role and therapeutic characteristics of black chokeberry (Aronia malanocarpa) in prevention of civilization-related diseases. Bromat Chem Toksykol XLII: 10-17.

Singleton VL, Orthofer R, Lamuela-Raventos RM (1999) Analysis of total phenols and other oxidation substrates and antioxidants by means of folin-ciocalteu reagent. Methods Enzymol 299: 152-178.

Suarez B, Alvarez AL, Garcia YD, del Barrio G, Lobo AP, Parra F (2010) Phenolic profiles, antioxidant activity in 
vitro antiviral properties of apple pomace. Food Chem 120: 339-342.

Tabart J, Kevers C, Pincemail J, Defraigne J-O, Dommes J (2009) Comparative antioxidant capacities of phenolic compounds measured by various tests. Food Chem 113: 1226-1233.

Vulic JJ, Tumbas VT, Savatovic SM, Dilas SM, Cetcovic GS, Canadanovic-Brunet JM (2011) Polyphenolic content and antioxidant activity of the four berry fruit pomae extract. Acta Periodica Technol (Apteff) 42: 271-279.

Vossen E, Ntawubizi M, Raes K, Smet K, Huyghebaert G, Arnouts S, De Smet S (2011) Effect of dietary antioxidant supplementation on the oxidative status of plasma in broilers. J Anim Physiol Anim Nutr (Berl) 95: 198-205.

Wiegand H, Boesch-Saadatmandi C, Regos I, Treutter D, Wolffram S, Rimbach G (2009) Effects of quercetin and catechin on hepatic glutathione-S transferase (GST), $\mathrm{NAD}(\mathrm{P}) \mathrm{H}$ quinone oxidoreductase 1 (NQO1), and antioxidant enzyme activity levels in rats. Nutr Cancer 61: 717-722.

Wolffram S, Lühring M, Blank R (2009) Flavonoids supplement vitamin supply. Kraftfutter 1/2: 23-29.

Yen GC, Chen HY (1995) Antioxidant activity of various tea extracts in relation to their antimutagenicity. J Agric Food Chem 43: 27-32.

Zduńczyk Z, Jankowski J (2013) Poultry meat as functional food: modification of the fatty acid profile: a review. Annals Anim Sci 13: 463-480.

Zduńczyk Z, Drażbo A, Jankowski J, Juskiewicz J, Czech A, Antoszkiewicz Z (2013) The effect of different dietray levels of vitamin $\mathrm{E}$ and selenium on antioxidant status and immunological markers in serum of laying hens. Pol J Vet Sci 16: 333-339. 